Journal Article

\title{
Aerospace composite cured by quickstep and autoclave processing techniques: Evaluation and comparison of reaction progress
}

Khan, L.A., Kausar, A, Day, R.J.

This article is published by Elsevier. The definitive version of this article is available at:

http://www.sciencedirect.com/science/article/pii/S1270963816306745

Recommended citation:

Khan, L.A., Kausar, A, Day, R.J., (2017) 'Aerospace composite cured by quickstep and autoclave processing techniques: Evaluation and comparison of reaction progress', Aerospace Science and Technology, Volume 65, June 2017, Pages 100-105. doi: 10.1016/j.ast.2017.02.014. 


\section{Accepted Manuscript}

Aerospace composite cured by quickstep and autoclave processing techniques: Evaluation and comparison of reaction progress

Laraib A. Khan, Ayesha Kausar, Richard J. Day

PII:

S1270-9638(16)30674-5

DOI: $\quad$ http://dx.doi.org/10.1016/j.ast.2017.02.014

Reference: $\quad$ AESCTE 3923

To appear in: $\quad$ Aerospace Science and Technology

Received date: 17 September 2016

Revised date: 3 February 2017

Accepted date: 16 February 2017

Please cite this article in press as: L.A. Khan et al., Aerospace composite cured by quickstep and autoclave processing techniques: Evaluation and comparison of reaction progress, Aerosp. Sci. Technol. (2017), http://dx.doi.org/10.1016/j.ast.2017.02.014

This is a PDF file of an unedited manuscript that has been accepted for publication. As a service to our customers we are providing this early version of the manuscript. The manuscript will undergo copyediting, typesetting, and review of the resulting proof before it is published in its final form. Please note that during the production process errors may be discovered which could affect the content, and all legal disclaimers that apply to the journal pertain. 


\title{
Aerospace Composite Cured by Quickstep and Autoclave Processing Techniques: Evaluation and Comparison of Reaction Progress
}

\author{
Laraib A. Khan a, Ayesha Kausar ${ }^{\text {b,* }}$, and Richard J. Day ${ }^{c}$ \\ ${ }^{a}$ Center for Emerging Sciences, Engineering and Technology, Islamabad, Pakistan \\ ${ }^{b}$ Nanoscience and Technology Department, National Centre For Physics, Islamabad, Pakistan \\ ${ }^{c}$ Glyndwr University, Mold Road, Wrexham, Wales LL11 2AW, UK \\ *Corresponding author. Tel.: 0092-51-2077-300 \\ E-mail:dr.ayeshakausar@yahoo.com
}

\begin{abstract}
Quickstep is relatively a new technique for aerospace composite processing. Thermoset resins (prepregs) have been frequently designed by autoclave method requiring low ramp rate curing of 2-3 $\mathrm{K} \min ^{-1}$. However, ramp rate up to $15 \mathrm{~K} \mathrm{~min}^{-1}$ have been achieved via Quickstep processing. This technique allows alteration in chemo-rheology of resin system and so influences the reaction progress. In this attempt, Fourier transform infrared spectroscopy (FTIR), differential scanning calorimetry (DSC), and dynamic mechanical thermal analysis (DMTA) were used to monitor the cure progress of 977-2A epoxy resin and carbon fiber reinforced composite. The curing reaction progress of 977-2A epoxy/carbon fiber was considered for the first time by comparing Quickstep processing and autoclave method. According to DSC results, the reaction progress in Quickstep technique was comparable to that of autoclave curing. Moreover, DMTA of Quickstep cured samples showed increase in glass transition temperature $\left(\mathrm{T}_{\mathrm{g}}\right)$ due to increased cross-linking density at greater hold time (upper cure temperature). FTIR was used to monitor the conversion of representative functional groups versus applied Quickstep and autoclave curing steps. The structural analysis depicted that the Quickstep
\end{abstract}


curing path for 977-2A resin was different than the autoclave curing; however the final cross-linked structure was similar to that of autoclave cured samples.

Keywords: Epoxy; carbon fiber; Quickstep; curing; $\mathrm{T}_{\mathrm{g}}$.

\section{Introduction}

Quickstep was designed and developed in Australia for out-of-autoclave (OOA) processing of low cost and high quality components in comparatively shorter cure cycle time than traditional autoclave and oven cure techniques. This technique relies on unique fluid filled, balanced pressure, floating mold technology for the curing, partial curing and joining of prepregs, and dry fiber/wet resin-based composites [1-3]. In Quickstep technique, the laminate is sandwiched between two floating rigid or semi rigid molds. Heat is rapidly applied through heat transfer fluid (HTF). The laminate and the mold are separated from HTF by flexible membranes. Due to flow of HTF, a ramp rate of about 12-15 K$\min ^{-1}$ can be achieved, which is much higher than $2-3 \mathrm{~K}-\mathrm{min}^{-1}$ ramp rate (autoclave curing). The higher ramp rate in Quickstep may change chemo-rheology of applied resin system. Cure behavior and optimization of an important aerospace grade 977-2A epoxy resin have been investigated for change in chemo-rheology [4, 5]. Similarly, processing and properties of other aerospace resins have been studied using Quickstep technique [6-8]. However, little work has been reported so far regarding the design of optimized cure cycle for Quickstep processing based on structural mechanical characterization [9]. In order to determine the optimum processing parameters for Quickstep processing, two important concepts have been used i.e. adequate fiber wetting and appropriate intermediate dwell time. The vacuum bagging arrangement in Quickstep processing have been manipulated to reduce void content and thus total cycle time $[4,5]$. Moreover, statistical analysis was performed on data obtained from physical and mechanical characterization. It was observed that integration of double vacuum bag technique with Quickstep processing was not statistically significant

[5]. In aerospace composite, wetting of matrix/fiber interface is an important factor for desired 
properties of final material. Quickstep technique is also an important manufacturing process contributing the quality of fibre/matrix interface. Effect of hygrothermal conditioning on physical and mechanical properties of 977-2A carbon/epoxy composites were explored [4]. It was observed that Quickstep cured panels absorbed slightly higher moisture content due to high resin content and crosslink density (relative autoclave cured panel).

A few reports have been published regarding the comparison of cured characteristics of aerospace composites manufactured using Quickstep vs. autoclave [10-13]. The properties compared between the two processes were glass transition temperature $\left(\mathrm{T}_{\mathrm{g}}\right)$ and final chemical state of the cured laminates. It was observed that the Quickstep cured panels exhibited higher $T_{g}$ and fine chemical structure compared to the autoclave cured equivalents. Despite of the reported studies, few questions still needed to be answered. For example, how much the high ramp rate affects the cure reaction of epoxybased thermosets as compared to low ramp rate? Moreover, changes in thermal characteristics such as exothermic enthalpy of cure during different stages of cure cycles in Quickstep and autoclave processing are still unexplored. This work, thus, aims to answer the questions raised above using various analytical tools such as Fourier transform infrared spectroscopy (FTIR), differential scanning calorimetry (DSC), and dynamic mechanical thermal analysis (DMTA). Aerospace grade 977-2A epoxy/carbon fiber composite laminates have been developed using Quickstep processing as well as by autoclave method. Researchers in this field have recommended DSC and DMTA for determination of degree of cure and for developing cure cycles of thermosetting resin and prepregs $[14,15]$. DSC also measures the heat flow required to maintain a sample at a given temperature, thus providing information on cure and reaction. DMTA monitors the enhancement of cross-link density as the diffusion-based reaction progress, particularly in case of epoxy systems. In addition, FTIR is an efficient technique for structural characterization of aerospace materials. In case of 977-2A epoxy/carbon fiber composite, DSC, DMTA, and FTIR were used to determine the effect of high ramp 
rate on the cure reactions at different stages of cure cycles employed for Quickstep and autoclave processing.

\section{Experimental}

\subsection{Material}

The material used for manufacturing all the panels (Quickstep/autoclave) was Cytec Cycom ${ }^{\circledR 977-2 A}$ based prepregs with epoxy resin and woven 6K HTA carbon fiber. The volume fraction of $63 \%$ was used. The cured ply thickness was $0.36 \mathrm{~mm}$.

\subsection{Techniques and Instrumentation}

\subsubsection{Autoclave cure cycle}

The manufacturer's recommended cure cycle was employed for autoclave curing. The cured characteristics were investigated on different steps of the cure schedule (Table 1).

\subsubsection{Quickstep cure cycle}

The initial steps of an optimized cure cycle for Quickstep processing were designed based on rheology information of epoxy resin $[4,5]$. The curing steps involved in this cycle are shown in Table 1. The Quickstep processing plant is shown in Fig. 1.

\subsubsection{Differential scanning calorimetry (DSC)}

TA Instruments Q100 DSC was used to observe the curing behavior of Cycom 977-2A carbon/epoxy uncured and partially cured prepregs. About $10 \mathrm{mg}$ of sample encapsulated in an aluminum pan was placed in DSC sample cell and an empty pan was used as the reference. The Q100 is a heat flux DSC with temperature operating range of -80 to $700{ }^{\circ} \mathrm{C}$. All samples were measured under a nitrogen atmosphere with a purge flow rate of $50 \mathrm{~mL} \mathrm{~min}{ }^{-1}$. Four samples were used for each analysis. 


\subsubsection{Dynamic mechanical thermal analysis (DMTA)}

DMTA was carried out using a Perkin Elmer Pyris diamond dynamic mechanical analyzer. The dimensions of the composite test coupons cured in autoclave and Quickstep were $10 \mathrm{~mm}$ wide and 50 $\mathrm{mm}$ long, with the fiber direction aligned to the $50 \mathrm{~mm}$ length. The experimental parameters involve heating rate $\left(5 \mathrm{~K} \mathrm{~min}^{-1}\right)$, frequency $(1 \mathrm{~Hz})$, temperature $\left(30-300{ }^{\circ} \mathrm{C}\right)$, and peak of tan $\delta$ curve considered as $\mathrm{T}_{\mathrm{g}}$ for all the samples. The specimens were stored in sealed plastic bags and tested within 15 days after the manufacturing activity. Four samples were tested for each analysis.

\subsubsection{Fourier Transform Infrared (FTIR) spectroscopy}

A Thermo Electron Nicolet 5700 FT-IR spectrophotometer with a small orbit diamond ATR disc was used. A resolution of $4 \mathrm{~cm}^{-1}$ and 32 scans in spectral range of 4000 to $400 \mathrm{~cm}^{-1}$ were used to obtain the spectra. Attenuated total reflectance (ATR)-FTIR is a form of reflectance spectroscopy which yields information about the surface properties of a material unlike transmission spectroscopy, which yields information about the bulk properties of the sample.

\section{Result and Discussion}

\subsection{Differential scanning calorimetric study}

A detailed analysis regarding the degree of cure obtained from the two processing techniques have been reported previously [4]. It was observed that the heating rate greatly affect the cure process. The degree of cure obtained from the autoclave cure (91.4\%) was taken as benchmark and the optimum time at upper cure temperature i.e. $180{ }^{\circ} \mathrm{C}$ was determined for Quickstep processing. It was observed that the 120 min at upper cure temperature gave comparable degree of cure as that of autoclave cure cycle. Using DSC, it was possible to follow the degree of cure at various stages of Quickstep cure cycle while comparing with traditional autoclave curing. In order to determine the degree of cure at different stages of cure cycles, samples of the prepregs were used. The steps of cure cycles were simulated in DSC. After reaching the required stage, the samples were cooled down to room 
temperature quickly and then dynamic heating was applied at $3 \mathrm{~K} \mathrm{~min}^{-1}$ from $25-300{ }^{\circ} \mathrm{C}$. Measurement of the cumulative increase in degree of cure at various steps of cure cycles in Quickstep and autoclave cycles are shown in Fig. 2. It can be seen from Fig. 2B that the degree of cure increases steadily as the cure cycle progress for the autoclave curing. Owing to low ramp rate, the extent of cure was approximately $22 \%$ and $37 \%$ at the start of two dwell temperatures at 130 and $180{ }^{\circ} \mathrm{C}$. However, the major portion of curing reaction $(\sim 60 \%)$ occurs at the hold time of upper curing temperature $\left(180{ }^{\circ} \mathrm{C}\right)$. It can also be observed that the majority of curing reaction occurred at the upper curing temperature $\left(180^{\circ} \mathrm{C}\right)$, irrespective of the cure cycle. The final degree of cure at the end of the cycle, however, strongly depends on the time spent at the upper cure temperature and curing reactions in initial steps of the cure cycle. The incorporation of additional dwell (step ' $b$ ' Table 1) in the Quickstep cure cycle comparable degree of cure to that of autoclave cure cycle (Fig. 2A). Subsequent to the intermediate dwell period, $33 \%$ and $37 \%$ degree of cure were achieved on reaching the final dwell temperature of $180^{\circ} \mathrm{C}$ for Quickstep and autoclave cycles, respectively. Fig. 3 includes details of the steps/stages of cure cycles considered for quickstep and autoclave processes. Consequently, an additional information about the degree of cure at different stages of Quickstep cure is provided in Fig. 3B. It can be seen that after curing for $60 \mathrm{~min}$ at $180{ }^{\circ} \mathrm{C}$, Quickstep cured samples exhibited similar degree of cure as compared to autoclave cure (Fig. 3A). Despite of the difference in cure cycles, the final degree of cure obtained for autoclave and Quickstep cure cycles were 91.4\% and 91.3\%, respectively. This shows almost comparable degree of cure obtained using the two cure schedules, which may be attributed to the cure reaction at additional dwell stage i,e. step 'b' (Table 1) in the Quickstep cure cycle.

\subsection{Spectroscopic analysis}

In this study, the cure process of epoxy and carbon fiber composites manufactured using autoclave and Quickstep has been analyzed using FTIR. With this technique, it was possible to follow the curing reactions and conversion of different representative functional groups as a function of applied curing steps (Quickstep and autoclave). Since, information about the functional groups, chemical compounds, 
and their concentration in 977-2A epoxy resin was proprietary; it was difficult to ascertain the detailed chemistry of 977-2A resin. Characteristics peaks were compared under different processing conditions to observe the effect on different functional groups present. Moreover, for comparative reasons the intensity of each peak in FTIR spectra was normalized against the intensity of aliphatic hydrocarbon group peak $\left(2930 \mathrm{~cm}^{-1}\right)$. Aliphatic hydrocarbon groups do not participate in any of the cure reactions, thus their band intensity remains constant during the curing process. The important peaks studied are given in Table $2[16,17]$. The different stages of cure cycles (autoclave and Quickstep) considered for FTIR analysis is shown in Fig. 3. For the ease of discussion, cumulative degree of cure obtained from DSC analysis is also provided. The points highlighted in spectra are (I) uncured state (II) at the start of $130{ }^{\circ} \mathrm{C}$; (III) at the start of $180{ }^{\circ} \mathrm{C}$; (IV) after $60 \mathrm{~min}$ at $180{ }^{\circ} \mathrm{C}$; and (V) fully cured. The polymerization mechanism of an epoxy/amine system typically includes three fundamental reactions: (a) primary amine-epoxy ring opening reaction which produces secondary amine and hydroxyl group; (b) secondary amine epoxy reaction to form tertiary amine and second hydroxyl group; and (c) etherification reaction, in which pendant hydroxyl groups react with the epoxide functionality. These reactions may be incomplete because of diffusion or steric restrictions or due to side reactions like the homo-polymerization of epoxide group [18].

In order to obtain the FTIR spectra at different stages of the cure cycles, samples of uncured prepregs were used and steps of cure cycles were simulated in DSC. After reaching the required stage, the samples were removed from DSC instrument and the upper sealed lid was carefully removed using sharp cutter. The samples were then straightaway tested to get the FTIR spectra. The FTIR spectra corresponding to the uncured prepregs and the samples (stages of cure cycles simulated in DSC) for the Quickstep and autoclave cure cycles are shown in Fig. 4 and 5, respectively. For clarity, enlarged views of the spectra in two spectral ranges $\left(1800-600\right.$ and $\left.3600-2800 \mathrm{~cm}^{-1}\right)$ are provided. The most salient feature was the decrease of epoxide absorption at $912 \mathrm{~cm}^{-1}$ and increase in intensity of hydroxyl peak at $3380 \mathrm{~cm}^{-1}$ due to polymerization. Since, the hydroxyl concentration of the curing mixture was 
increased as the polymerization reaction proceeded. It can be seen from Fig. 4B and Fig. 5B that three amine stretching vibrations were observed at $3469 \mathrm{~cm}^{-1}, 3369 \mathrm{~cm}^{-1}$ and $3242 \mathrm{~cm}^{-1}$ in the spectra of uncured prepregs. As the cure reaction proceeds from stage I to stage III, the two humps (characteristics bands at 3242 and $3469 \mathrm{~cm}^{-1}$ ) start to disappear due to epoxy-amine reaction. This can be clearly observed through complete disappearance of these characteristics peaks after stage IV for cured sample (both for Quickstep and autoclave cure schedules). In both the curing processes, appearance of a peak between 3600 and $3200 \mathrm{~cm}^{-1}$ can be noted, after the stages IV and V. This peak was attributed to the broadening of hydroxyl group that appeared as a result of amino-epoxy and other associated reactions. Moreover, its broad range was an evidence of formation of hydrogen bonds [16].

It is evident from Fig. 4B and Fig. 5B that the intensity of hydroxyl peaks remained almost same for both Quickstep and autoclave cure. An amine bending vibration also appeared at $1630 \mathrm{~cm}^{-1}$. However, after stage III amine peak at $1630 \mathrm{~cm}^{-1}$ completely disappeared in both the cases (Quickstep cure and autoclave). The curing process of an epoxy resin is usually dominated by a gel point where primary amine disappears [16]. Before the gelation point, a kind of linear polymerization (chain extension) takes place due to epoxy-amine reaction which is followed by branch reactions and cross linking due to secondary amine formation. It is important to note that the gel point for both cases was observed after $8-10 \mathrm{~min}$ at $180^{\circ} \mathrm{C}$. The peaks at 1294,1103 and $1036 \mathrm{~cm}^{-1}$ were assigned to ether stretching. It can be seen from Fig. $4 \& 5$ that the peaks at 1294,1103 and $1036 \mathrm{~cm}^{-1}$ were present for cured samples, nevertheless intensity decreased compared to that of uncured state. The occurrence of etherification in a curing system may vary the structure and associated macroscopic properties of the final product. As a result, cross linking reactions in resin may increase [19]. Comparing directly the spectra of cured composite, difference in intensity of some peaks can be observed during cure cycles. In particular, the respective peak intensity at 1294,1103 and $1036 \mathrm{~cm}^{-1}$ were significantly decreased between stage III and IV for autoclave cure. While for Quickstep cure, this happened between stages IV and V. This suggests that the epoxide-hydroxyl etherification reaction occurred more readily during 
autoclave curing than Quickstep cure of 977-2A carbon/epoxy composite. From Fig. 4 \& 5, it can be observed that the ether linkages have formed during later stages of cure cycle, after primary amine and epoxide reaction. Moreover, it was not affected by different cure cycles employed for Quickstep and autoclave cure. The final intensity of respective ether linkages for autoclave and Quickstep cure were same. In other words, the final network structure formed was same for both the cure cycles, despite the effect of different heating rates on reaction mechanism.

\subsection{DMTA analysis}

DMTA is another tool to monitor cure progress and cure state of polymeric composites. Due to cross-linking reaction, change in mechanical parameters with respect to temperature yields valuable information about the cure state [20-23]. Several researchers have reported the efficacy of DMTA for the detection of glass transition temperature and the cure state [24-27]. The variation of $\mathrm{T}_{\mathrm{g}}$ because of the altered hold time at upper cure temperature $\left(180^{\circ} \mathrm{C}\right)$ for Quickstep processing is shown in Fig. 6. Due to high cost of autoclave processing, the same activity could not be carried out for autoclave samples. However, the previously determined $\mathrm{Tg}$ of the samples cured in autoclave was $195{ }^{\circ} \mathrm{C}[5]$. The cure schedule mentioned in Fig. 2B was taken as reference for the comparative study of the two processes. It is evident from Fig. 6 that as the hold time was increased, the degree of cure and crosslink density were also increased resulting in higher $\mathrm{T}_{\mathrm{g}}$ of $>200^{\circ} \mathrm{C}(140 \mathrm{~min})$ [28-31].

\section{Conclusion}

DSC, DMTA and FTIR were used to determine the cured characteristics of Quickstep cured panel processed using optimum processing parameters. The properties were then compared with the samples cured by autoclave method. The degree of cure was measured at different stages of Quickstep and autoclave cure cycles. It was observed that the final degree of cure strongly depends on the time spent at upper cure temperature and slightly on the initial steps of cure cycle, which was in turn controls the resin flow, fiber wetting, and void removal. Moreover FTIR was employed to investigate the chemical 
species evolved during the cure. The final chemical structure of the composite panels cured in autoclave and Quickstep were also compared. The reaction path followed by the Quickstep cured sample was affected by different heating rates. However, the final network structure was similar to the autoclave cured samples.

\section{Acknowledgement}

The authors gratefully acknowledge Higher Education Commission (HEC) of Pakistan for providing financial support to pursue the research in the field of Composites manufacturing.

\section{Reference}

1. Z. Wang, Y. Jia, S. Xu, L. Tang, Active vibration suppression in flexible spacecraft with optical measurement, Aerosp. Sci. Technol. 55 (2016) 49-56.

2. A.K. Barouni, D.A. Saravanos, 2016. A layerwise semi-analytical method for modeling guided wave propagation in Laminated and sandwich composite strips with induced surface excitation, Aerosp. Sci. Technol. 51 (2016) 118-141.

3. W.Z. Xie, Y. Ge, H. Chen, Y.F. Wen, S. M. Guo, Rapid supersonic performance prediction for 2D ramjet inlets, Aerosp. Sci. Technol. 53 (2016) 220-231.

4. L.A. Khan, A. Nesbitt, R.J. Day, Hygrothermal degradation of 977-2A carbon/epoxy composite laminates cured in autoclave and Quickstep, Compos. Part A: Appl. Sci.Manufact. 41(2010) 942-953.

5. L.A. Khan, A.H. Mahmood, S. Ahmed, R. J. Day, Effect of double vacuum bagging (DVB) in quickstep processing on the properties of 977-2A carbon/epoxy composites, Polym. Compos. 34(2013) 942-952.

6. S.L. Agius, K.J.C. Magniez, B.L. Fox, Cure behaviour and void development within rapidly cured out-of-autoclave composites, Compos. Part B: Engineer. 47(2013) 230-237. 
7. J. Zhang, B. Fox, Characterization and analysis of delamination fracture and nanocreep properties in carbon epoxy composites manufactured by different processes, J. Compos. Mater. 40(2006) 12871299.

8. J. Zhang, B. Fox, Manufacturing influence on the delamination fracture behavior of the T800H/3900-2 carbon fiber reinforced polymer composites. Mater. Manufact. Process. 22(2007) 768772.

9. L. Davies, R.J. Day, D. Bond, A. Nesbitt, J. Ellis, E. Gardon, Effect of cure cycle heat transfer rates on the physical and mechanical properties of an epoxy matrix composite, Compos. Sci. Technol. 67 (2007) 1892-1899.

10. M.D. Silcock, C. Garschke, W. Hall, B. L. Fox, Rapid composite tube manufacture utilizing the quickstepTM process, J. Compos. Mater. 41(2007) 965-978.

11. M.L. Costa, E.C. Botelho, J.M.F.D. Paiva, M.C. Rezende, M.C. Characterization of cure of carbon/epoxy prepreg used in aerospace field, Mater. Res. 8 (2005) 317-322.

12. C. Garschke, C. Weimer, P.P. Parlevliet, B. L. Fox, Out-of-autoclave cure cycle study of a resin film infusion process using in situ process monitoring, Compos. Part A: Appl. Sci. Manufact. 43(2012) 935-944.

13. K.B. Katnam, L.F.M. Da Silva, T.M. Young, Bonded repair of composite aircraft structures: A review of scientific challenges and opportunities, Prog. Aerosp. Sci. 61 (2013) 26-42.

14. M.R. Dusi, R.M. Galeos, M.G. Maximovich, Physiorheological characterization of a carbon/epoxy prepreg system, J. Appl. Polym. Sci. 30(1980) 1847-1857.

15. S.L. Agius, K.J. Magniez, B.L.Fox, Fracture behaviour of a rapidly cured polyethersulfone toughened carbon fibre/epoxy composite, Compos. Structur. 92(2010), 2119-2127.

16. M. Sánchez-Soto, P. Pagés, T. Lacorte, K. Briceño, F. Carrasco, Curing FTIR study and mechanical characterization of glass bead filled trifunctional epoxy composites, Compos. Sci. Technol. 67(2007) 1974-1985. 
17. R.E. Smith, F.N. Larsen, C.L. Long, Epoxy resin cure. II. FTIR analysis. J. Appl. Polym. Sci. 29(1984) 3713-3726.

18. R.J. Morgan, F.-M. Kong, C.M. Walkup, Structure-property relations of polyethertriamine-cured bisphenol-A-diglycidyl ether epoxies, Polymer, 25(1984) 375-386.

19. L. Xu, J.R. Schlup, Etherification versus amine addition during epoxy resin/amine cure: An in situ study using near-infrared spectroscopy, J. Appl. Polym. Sci. 67(1998) 895-901.

20. K. Yu, M. Wang, J. Wu, K. Qian, J. Sun, X. Lu, Modification of the Interfacial Interaction between Carbon Fiber and Epoxy with Carbon Hybrid Materials, Nanomaterials. 6(2016) 89.

21. B. Nuhiji, D. Attard, A. Deveth, J. Bungur, B. Fox, The influence of processing techniques on the matrix distribution and filtration of clay in a fibre reinforced nanocomposite, Compos. Part B: Engineer. 2016. 84(2016) 1-8.

22. X. Jin, W. Wang, C. Xiao, T. Lin, L. Bian, P. Hauser, Improvement of coating durability, interfacial adhesion and compressive strength of UHMWPE fiber/epoxy composites through plasma pre-treatment and polypyrrole coating, Compos. Sci. Technol. 128 (2016) 169-175.

23. P.S. Gouda, J.D.Williams, M. Yasaee, V. Chatterjee, D. Jawali, S.S.Rahatekar, M.R. Wisnom, Drawdown prepreg coating method using epoxy terminated butadiene nitrile rubber to improve fracture toughness of glass epoxy composites, J. Compos. Mater. 50(2016) 873-884.

24. J.W. Yu, J. Jung, Y.M. Choi, J.H. Choi, J. Yu, J.K. Lee, N.H. You, M. Goh, Enhancement of the crosslink density, glass transition temperature, and strength of epoxy resin by using functionalized graphene oxide co-curing agents, Polym. Chem. 7(2016) 36-43.

25. W. Stark, M. Jaunich, J. McHugh, Dynamic Mechanical Analysis (DMA) of epoxy carbon-fibre prepregs partially cured in a discontinued autoclave analogue process, Polymer Testing, 41(2015) 140148. 
26. J. Michels, R. Widmann, C. Czaderski, R. Allahvirdizadeh, M. Motavalli, Glass transition evaluation of commercially available epoxy resins used for civil engineering applications, Compos. Part B: Engineer. 77 (2015) 484-493.

27. J. Michels, J. Sena-Cruz, C. Czaderski, M. Motavalli, Thermo-mechanical properties of commercially available epoxy resins for structural applications. in SMAR2015-Third Conference on Smart Monitoring, Assess. Rehabilit. Civil Struct. Sept 7 (2015) 1-8.

28. S. Kunnikuruvan, P.V. Parandekar, O. Prakash, T. K. Tsotsis, N.N. Nair, Insights into the Mechanism and Kinetics of Thermo-Oxidative Degradation of HFPE High Performance Polymer, J. Phys. Chem. B. 120 (2016) 4852-4860.

29. A.M. Coppola, A.S. Griffin, N.R. Sottos, S.R. White, Retention of mechanical performance of polymer matrix composites above the glass transition temperature by vascular cooling, Compos. Part A: Appl. Sci. Manufact. 78(2015) 412-423.

30. M. Ceraulo, M. Morreale, L. Botta, M.C. Mistretta, R. Scaffaro, Prediction of the morphology of polymer-clay nanocomposites, Polym. Test. 41 (2015) 149-156.

31. W. Stark, M. Jaunich, J. McHugh, Carbon-fibre epoxy prepreg (CFC) curing in an autoclave analogue process controlled by Dynamic Mechanical Analysis (DMA), Polym. Test. 32(2013) 14871494. 
Table 1. Steps of cure cycles employed.

\section{Autoclave Cycle}

a. Heat from room temperature to $130{ }^{\circ} \mathrm{C}$ at $2 \mathrm{~K} \mathrm{~min}^{-1}$

b. Dwell at $130{ }^{\circ} \mathrm{C}$ for $60 \mathrm{~min}$

c. Heat from $130{ }^{\circ} \mathrm{C}$ to $180^{\circ} \mathrm{C}$ at $2 \mathrm{~K} \mathrm{~min}^{-1}$

d. Dwell at $180{ }^{\circ} \mathrm{C}$ for $120 \mathrm{~min}$

e. Cool from $180^{\circ} \mathrm{C}$ to room temperature at $2 \mathrm{~K} \mathrm{~min}^{-1}$

\section{Quickstep Cycle}

a. Heat from room temperature to $175^{\circ} \mathrm{C}$ at $10-12 \mathrm{~K} \mathrm{~min}^{-1}$

b. Dwell at $175^{\circ} \mathrm{C}$ for $10 \mathrm{~min}$

c. Cool from $175^{\circ} \mathrm{C}$ to $130^{\circ} \mathrm{C}$ at 10-12 $\mathrm{K} \mathrm{min}^{-1}$

d. Dwell at $130{ }^{\circ} \mathrm{C}$ for $60 \mathrm{~min}$

e. Heat from $130{ }^{\circ} \mathrm{C}$ to $180{ }^{\circ} \mathrm{C}$ at $10-12 \mathrm{~K} \mathrm{~min}^{-1}$

f. Dwell at $180^{\circ} \mathrm{C}$ for $120 \mathrm{~min}$

g. Cool from $180^{\circ} \mathrm{C}$ to room temperature at $8-10 \mathrm{~K} \mathrm{~min}^{-1}$.

Table 2. Peak assignments for FTIR spectra.

\begin{tabular}{cc}
\hline Wavenumber $\left(\mathbf{c m}^{-\mathbf{1}}\right)$ & Functional group \\
\hline $3600-3200$ & $\mathrm{O}-\mathrm{H}$ (hydroxyl group) \\
3469 & $\mathrm{~N}-\mathrm{H}$ (secondary amine stretch) \\
3369 & $\mathrm{~N}-\mathrm{H}$ (secondary amine stretch) \\
3242 & $\mathrm{~N}-\mathrm{H}($ secondary amine stretch) \\
1630 & $\mathrm{~N}-\mathrm{H}$ (secondary amine bend) \\
1294 & Aromatic ether stretch \\
1103 & $\mathrm{C}-\mathrm{O}-\mathrm{C}$ (ether) \\
1036 & Ether group \\
912 & Epoxide group \\
\hline
\end{tabular}




\section{ACCEPTED MANUSCRIPT}

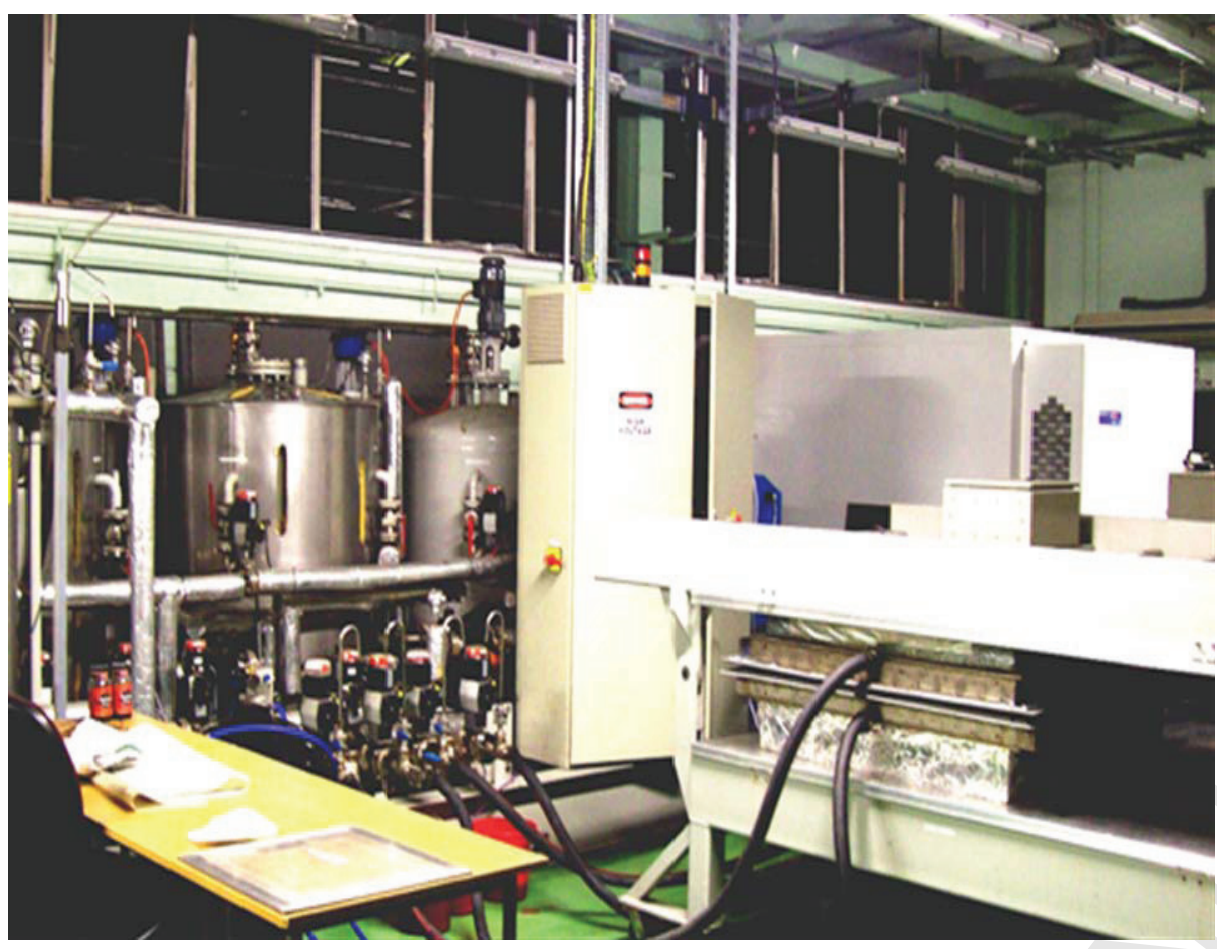

Fig. 1. Quickstep processing plant. 

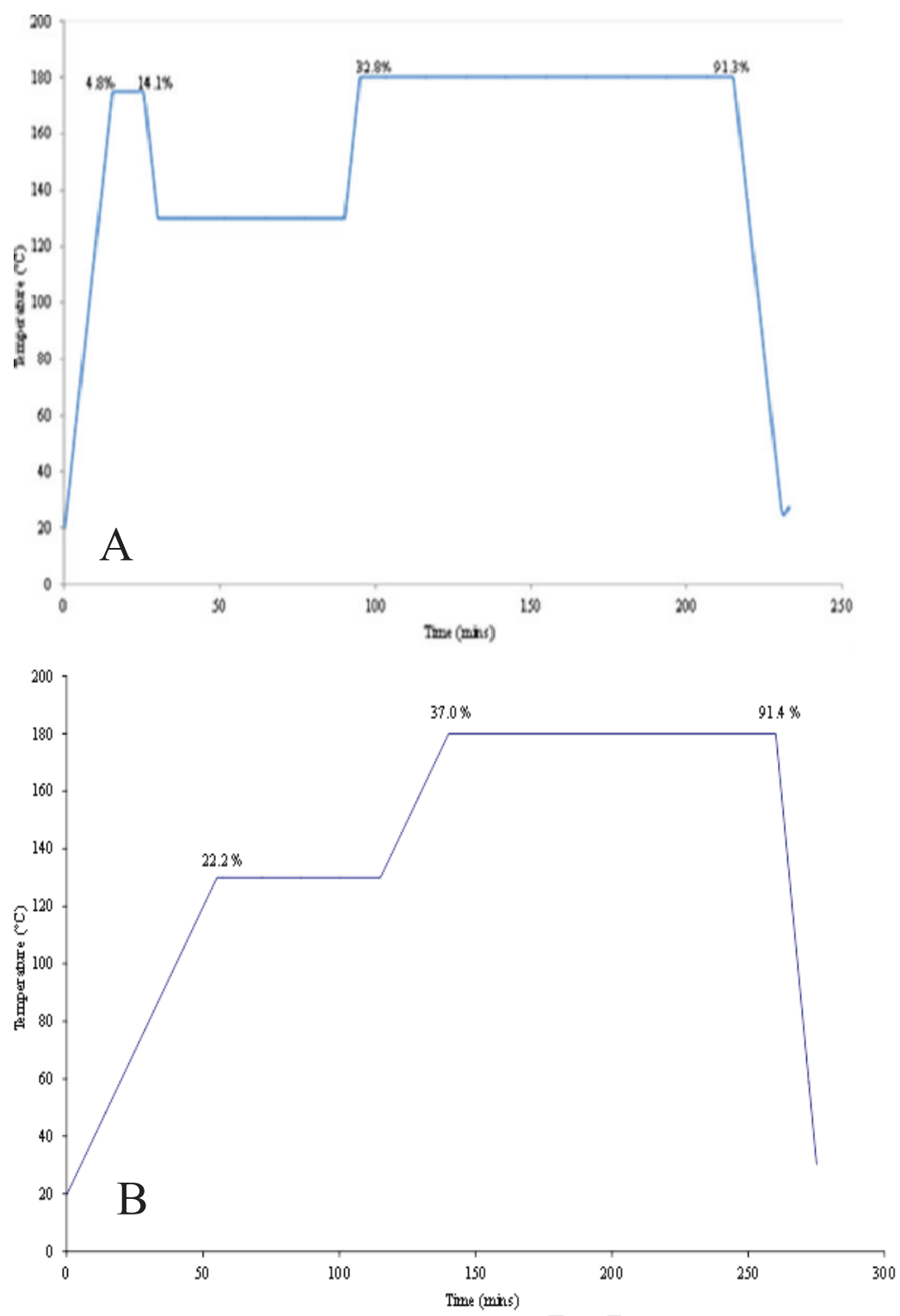

Fig. 2. Degree of cure at various stages of (A) Quickstep and (B) autoclave cycles. 

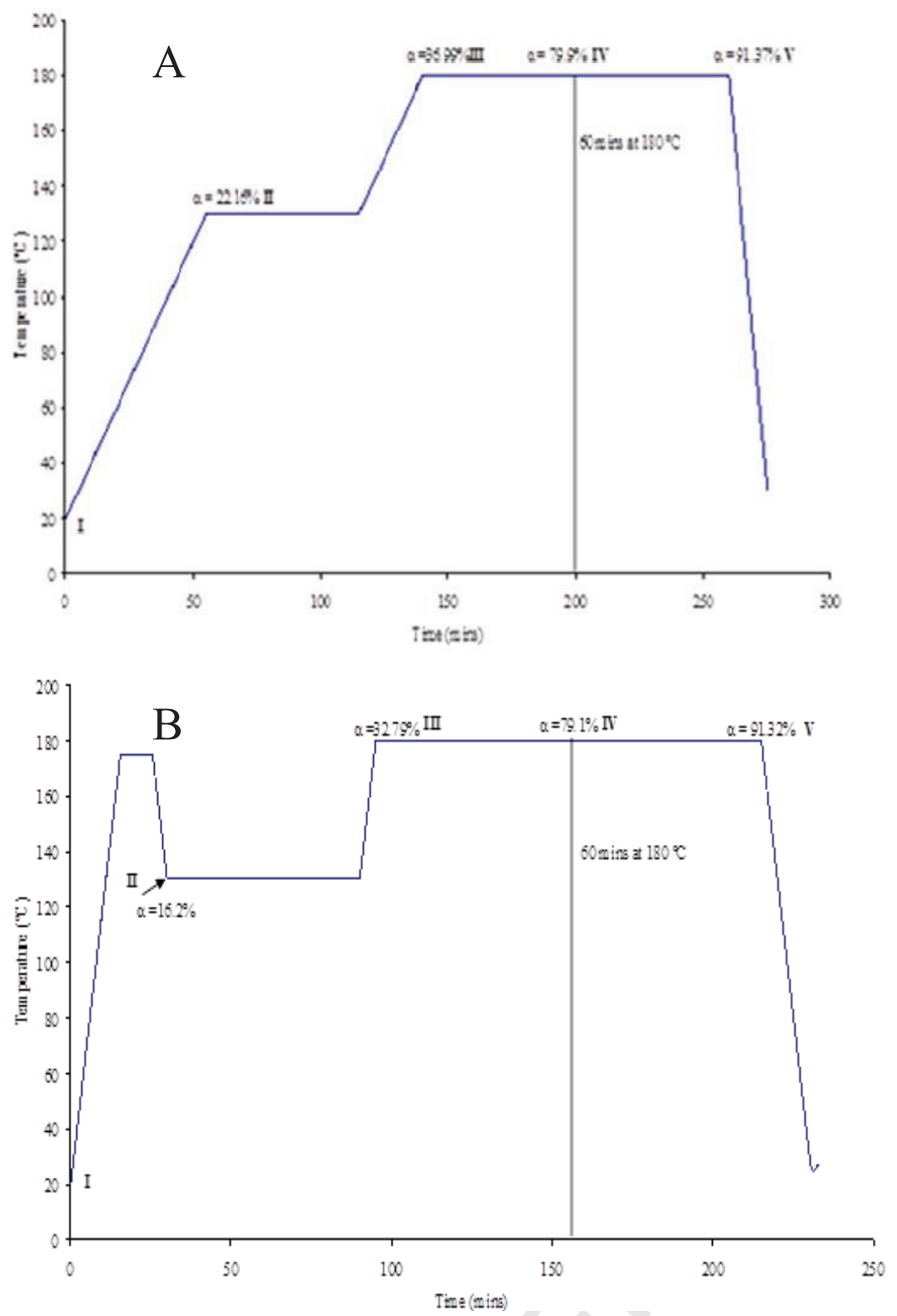

Fig. 3. Stages of cure cycles considered for FTIR analysis of (A) autoclave (B) Quickstep cure. 

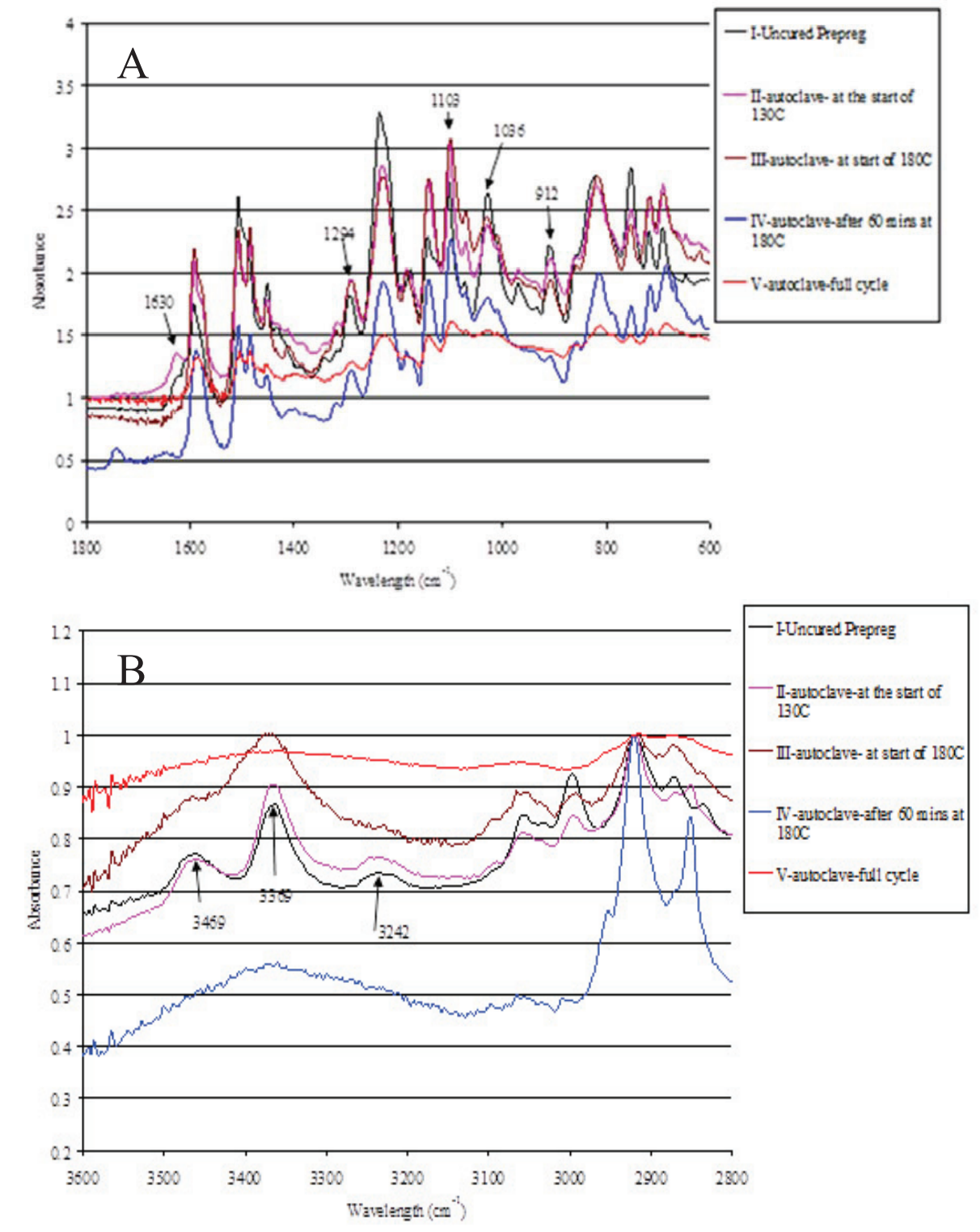

Fig. 4. Normalized FTIR spectra of uncured prepregs and prepreg subjected to steps of autoclave cure cycle simulated during DSC in spectral range of (A) $1800-600 \mathrm{~cm}^{-1}$ (B) $3600-2800 \mathrm{~cm}^{-1}$ 

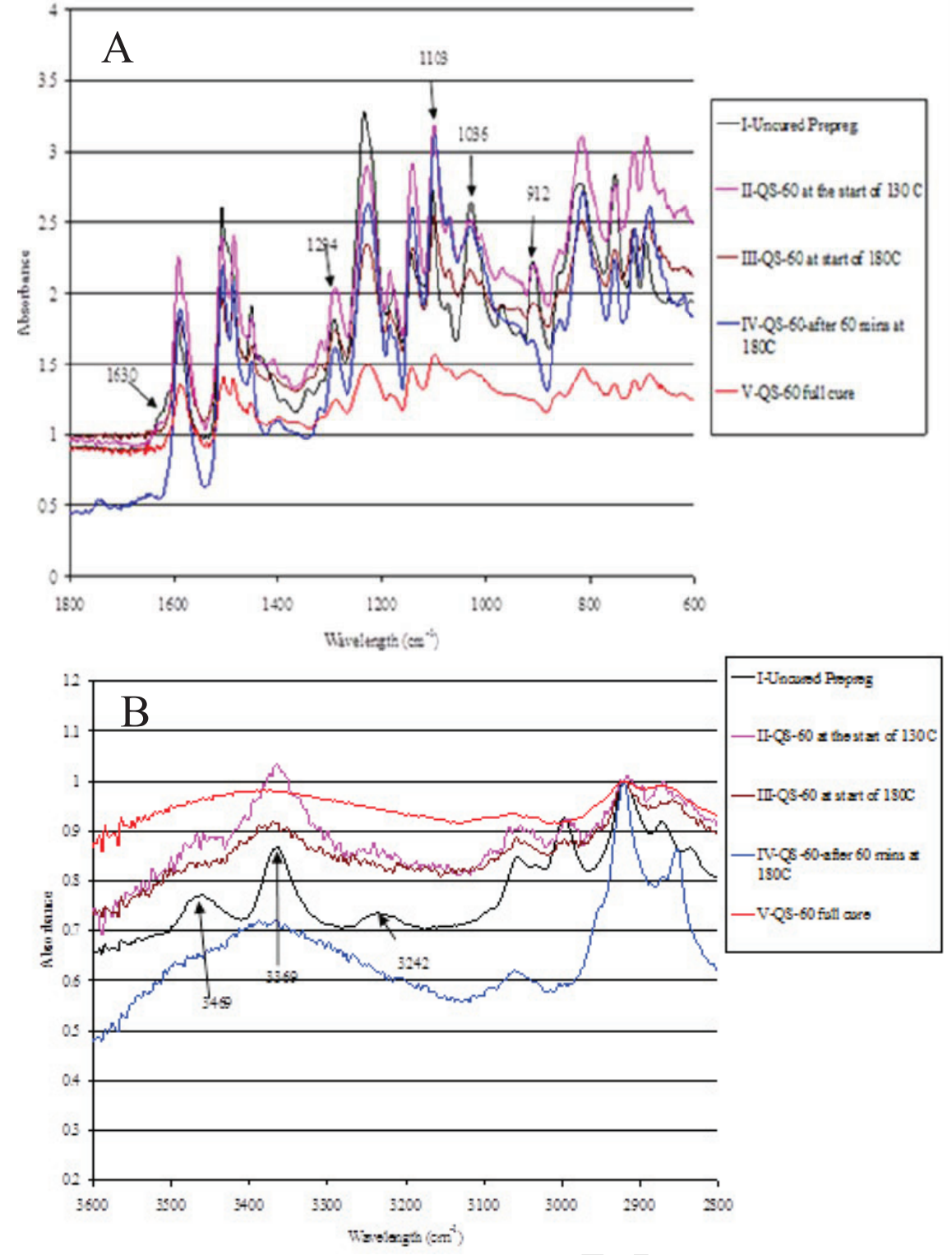

Fig. 5. Normalized FTIR spectra of uncured prepreg and prepreg subjected to Quickstep cure cycle simulated during DSC in spectral range of (A) $1800-600 \mathrm{~cm}^{-1}$ and (B) $3600-2800 \mathrm{~cm}^{-1}$. 
Quickstep- Tg Variation due to Changed hold time at Upper Cure Temperature $\left(180^{\circ} \mathrm{C}\right)$

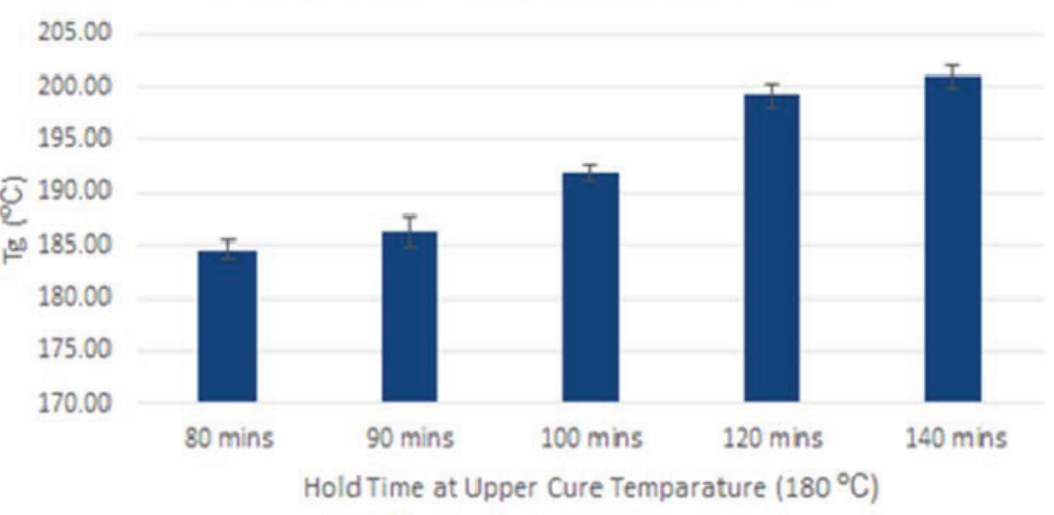

Fig. 6. Variation in $T_{g}$ with respect to hold time at upper cure temperature for Quickstep processing 